\title{
Resection of upper lip adenoid cystic carcinoma and reconstruction with reverse Yu flap: Report of three cases and a literature review
}

\author{
MARTA SANCHEZ-SANCHEZ ${ }^{1}$, PEDRO INFANTE-COSSIO ${ }^{1}$, RODRIGO LOZANO-ROSADO ${ }^{1}$, \\ LUIS-MIGUEL GONZALEZ-PEREZ ${ }^{1}$, MIGUEL-ANGEL JAPON-RODRIGUEZ ${ }^{2}$, JUAN-DAVID GONZALEZ-PADILLA ${ }^{1}$, \\ ANGEL MARTINEZ-SAHUQUILLO-MARQUEZ ${ }^{3}$ and RODOLFO BELMONTE-CARO ${ }^{1}$
}

Departments of ${ }^{1}$ Oral and Maxillofacial Surgery, and ${ }^{2}$ Pathology, Virgen Del Rocio University Hospital;

${ }^{3}$ Department of Oral Medicine, Faculty of Dentistry, University of Seville, 41013 Seville, Spain

Received September 22, 2015; Accepted January 24, 2017

DOI: $10.3892 / \mathrm{mco} .2017 .1150$

\begin{abstract}
The present study aimed to describe the techniques that were used, and the results obtained, with the reverse Yu flap to reconstruct medium-sized upper lip defects following resection for adenoid cystic carcinoma (ACC). Data concerning the clinical and pathological characteristics of tumours, the size and location of the defects, surgical resection and the reconstructive procedure used were evaluated in three patients, as well as postoperative complications and outcomes. In all cases, a complete surgical removal of ACC was achieved with clear margins of at least $1 \mathrm{~cm}$. Histopathological features revealed two cases with a predominant solid growth pattern, and one case of cribriform. Following tumour excision, the average size of the upper lip defect was $35.7 \times 30 \mathrm{~mm}$. The reverse Yu flap was raised simultaneously with tumour resection in all cases. No flap failed, and both excellent aesthetic and functional results were obtained. All the patients had a satisfactory oral competence, without microstomia, after a median of 20 months follow-up (range, 12-30 months). Adjuvant radiation therapy was not necessary in any case. On the basis of the present case study and literature review, reverse Yu flap is revealed to be a simple and reliable technique for the reconstruction of defects ranging from one-third to two-thirds of the total upper lip length, involving the commissure, nasolabial fold and philtrum, with minimal donor morbidity and a good functional and aesthetic outcome. This flap appears to be a valid surgical option for reconstruction of medium-sized upper lip defects, which may be considered following radical excision of ACC.
\end{abstract}

Correspondence to: Professor Pedro Infante-Cossio, Department of Oral and Maxillofacial Surgery, Virgen Del Rocio University Hospital, Manuel Siurot Avenue, 41013 Seville, Spain

E-mail: pinfante@us.es

Key words: adenoid cystic carcinoma, upper lip, lip reconstruction, Yu flap, combined rotation and advancement flap

\section{Introduction}

Adenoid cystic carcinoma (ACC) is a common salivary gland malignancy. Although its clinical and pathological features are well known, several controversial issues regarding its behaviour and management remain to this day. In the World Health Organization (WHO) classification (2005) (1), ACC was classified as a malignant epithelial tumour within the group of carcinomas. Histologically, this neoplasm is composed of two types of cells: Duct-lining and myoepithelial cells, arranged in two subtypes designated as glandular (cribriform) and solid patterns. Perzin et al (2) subsequently described a more differentiated ACC type: The tubular form. At present, there is no consensus on the association between the histological pattern and prognosis of ACC, although the solid pattern appears to be associated with a worse prognosis compared with other histological types $(3,4)$.

ACC accounts for 5-10\% of all salivary gland tumours (5). It is considered to be one of the most common malignant tumours that occur in minor salivary glands (6), representing $10-15 \%$ of all these neoplasms $(4,7)$. Intraorally, the palate is the most common site, comprising $~ 50 \%$ of all malignant palatal tumours $(3,8-14)$. Less common sites of involvement include the lower lip, retromolar-tonsillar pillar region, sublingual gland, buccal mucosa, and floor of the mouth (15-18). Waldron et al (4) reported that $5 \%$ of incidences of ACC of the minor salivary glands occurred in the upper lip.

Classically, the clinical behaviour of ACC is considered somewhat paradoxical. It is usually a slow-growing neoplasm with insidious evolution, although occasionally it may be very aggressive from the beginning. It tends to spread along perineural sheaths, causing neuropathic pain. High rates of local recurrences and distant hematogenous metastasis are frequent in this neoplasm, with lungs being the most common site (19). The ACC standard treatment is based on a complete surgical resection with a $1 \mathrm{~cm}$ clear margin. When located on the upper lip, tumour resection results in medium-to-large defects that require an immediate reconstruction to restore functional competence with optimal aesthetic outcome. Depending on the size and location of the lip defect, the patient's age and 
gender and the surgeon's experience, several techniques may be used to ensure the proper restoration of lip form and function. Established methods of reconstruction, including the Estlander (20), Karapanzic (21), or Gillies (22) flaps, yield good results, although multiple steps are often required. In 2010, the present authors reported, to the best of our knowledge for the first time, use of the reverse Yu flap for reconstruction of full-thickness defects up to half of the upper lip, involving the commissure, nasolabial fold and philtrum (23). This technique combines a buccal and mental rotation flap, an upper lip advancement flap, and a buccal mucosal flap. This approach produced a good functional and cosmetic outcome in a single-stage procedure.

The purpose of the present study was to retrospectively analyze three patients with ACC of the minor salivary gland located in the upper lip operated on at the Department of Oral and Maxillofacial Surgery, Virgen Del Rocio University Hospital, Seville, Spain, and to present our experience with the surgical excision and immediate reconstruction of labial defect using a reverse Yu flap.

\section{Patients and methods}

Between September 2012 and March 2014, three patients diagnosed with upper lip ACC underwent excision and primary reconstruction with a reverse $\mathrm{Yu}$ flap in the Virgen del Rocio University Hospital (Seville, Spain). The patients comprised two men and one woman aged from 66-80 years (mean, 73 years).

Surgical technique. Under general anesthesia, an inverted, heart-shaped, full-thickness upper lip excision was first performed, including the tumour with a macroscopically clear margin of $>1 \mathrm{~cm}$. Subsequently, the reverse Yu flap was raised to perform a primary lip reconstruction. Skin and subcutaneous tissue were horizontally incised from the labial commissure. This incision was slightly longer than the defect width when the flap was unilateral, and more than half of the defect width when bilateral. At this point, the orbicularis oris muscle on its medial half was partially cut, while the lateral half of the muscle was kept intact. Subsequently, a curved incision parallel to the nasolabial fold was made, and at the end, it continued almost perpendicularly to the horizontal line, which was approximately half of the distance between them. At this point in the operation, two flaps were designed: The superior advancement flap of the upper lip, which was pulled to the defect site, and the inferior rotating flap of the buccal and mental regions, which was moved to repair the donor site defect that was created by the advancement flap. The defect of the rotation flap was closed directly. Finally, a buccal mucosal flap was turned and pulled outwards to reconstruct the new vermilion of the upper lip, and the flap was sutured layer to layer. A non-absorbable monofilament 4/0 suture was used for orbicularis oris repair, subcutaneous sutures with $4 / 0$ vycril were used to relieve tension on suture lines, and skin was closed using nylon $4 / 0$ and 5/0. No nasogastric tube was routinely required, although the patient was provided with a soft diet for approximately one week following surgery.

Patient 1. A 66-year-old man presented with a painless submucosal nodule in the upper lip of $1.5 \mathrm{~cm}$ in diameter. Wide surgical excision followed by immediate reconstruction of a defect measuring $3 \times 2 \mathrm{~cm}$ with a reverse Yu flap was performed. Histopathological examination revealed an ACC with a predominant cribriform pattern without evidence of perineural spread (Fig. 1).

Patient 2. An 80-year-old woman presented with a nodule that had invaded the labial commissure. There was no evidence of regional nodal involvement or metastatic disease. Following tumour resection, the defect was $3.7 \times 3.5 \mathrm{~cm}$ in size, and a reverse Yu flap was used for reconstruction. Histologically, the lesion revealed a predominant solid pattern (Fig. 2).

Patient 3. A 74-year-old man with a history of partial gastrectomy for complicated duodenal ulcer, acute biliary pancreatitis with cholecystectomy, and a right lateral upper lip ACC resected 2 years earlier in a different hospital, presented with a solitary pulmonary nodule identified as an incidental finding. Positron emission tomography/computed tomography (PET/CT) suggested high suspicion of a malignancy. Pathology from the segmental resection revealed a lung metastasis from ACC of $3.3 \mathrm{~cm}$, and no systemic therapy was required. At 2 years follow-up, the patient presented with a swelling in the midline on the upper lip of $\sim 2$ months' duration. Intraoral examination of the labial mucosa revealed an oval submucosal nodule measuring $\sim 2 \mathrm{~cm}$, without ulceration and tenderness on palpation. The histopathological examination revealed a local recurrence of ACC, with a predominantly solid growth pattern, which required wide excision, creating a defect of $4 \times 3.5 \mathrm{~cm}$ and reconstruction with bilateral reverse Yu flap (Fig. 3).

\section{Results}

Two cases were located in the upper lip lateral side, and one in the midline (Table I). The main complaint in all patients was the appearance of an enlarging nodule on the upper lip. No patient reported spontaneous pain. The time elapsed from the onset of symptoms to diagnosis varied between 3-26 months. Patient 3 presented following a local recurrence of ACC, and evidence of distant lung metastasis. According to the predominant histological pattern, two cases revealed a solid pattern, and the other case, a cribriform one. In all patients, complete surgical excision with clear margins of at least $1 \mathrm{~cm}$ was achieved. The resulting defect ranged from one-third to two-thirds of the upper lip (mean, 35.7x30 mm). Two patients had unilateral flaps, and one patient had a bilateral one. No flap failed, and the aesthetic and functional outcome was very satisfactory. Postoperative radiotherapy was not administered in any case. Follow-up ranged from 12-30 months, and all patients remain free of disease. Oral competence was good, and there was no sign of microstomia. The residual scars remained camouflaged along the nasolabial fold and commissure, and the upper lip was symmetrical.

\section{Discussion}

ACC tumours located in the upper lip rarely occur, having been reported only in a very few cases to date in the literature. The first case was reported by Pizer and Dubois (24) in 1985, 
A

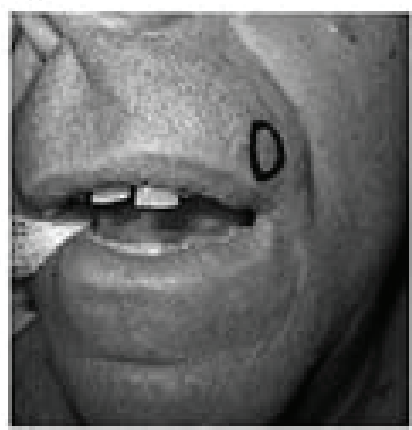

D

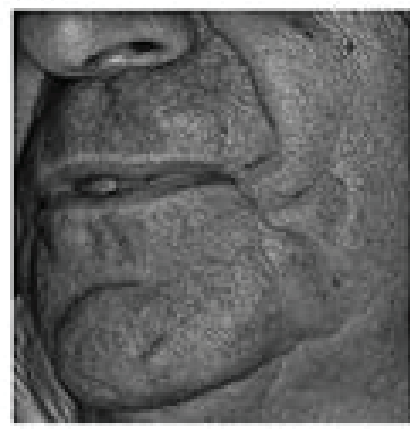

B

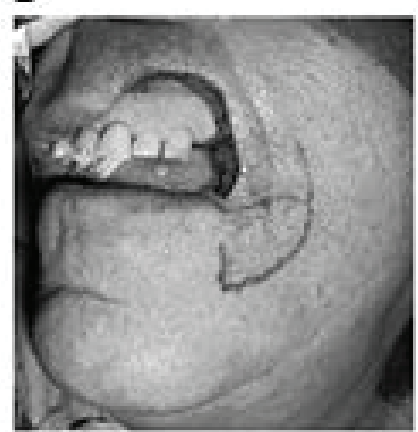

E

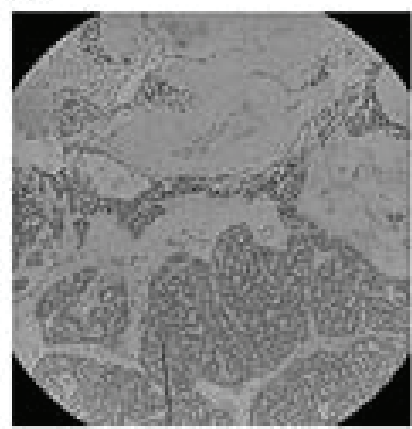

C

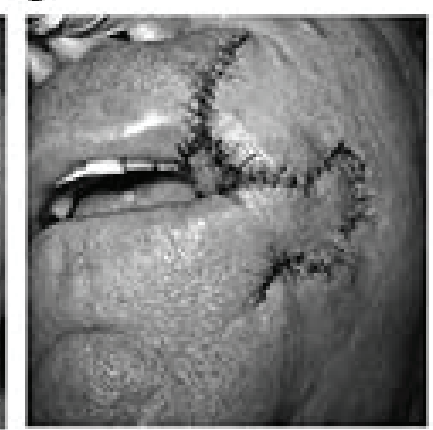

F

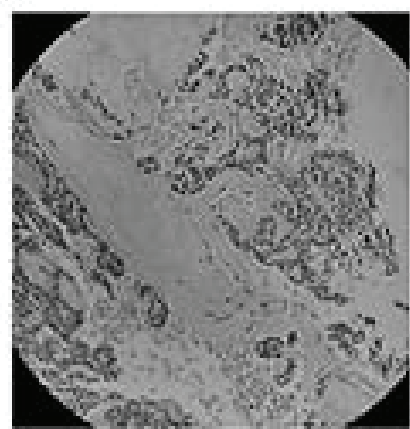

Figure 1. Case 1. (A) Preoperative view. (B) Intraoperative view following excision. (C) Immediate postoperative appearance, and (D) one year after the procedure. (E) Panoramic view of the histopathological examination revealed a typical ACC with a predominantly cribriform growth pattern (H\&E staining; magnification, x20). (F) Detail of the cribriform pattern, characterized by multiple epithelial nests moulded into a 'jigsaw puzzle' surrounded by eosinophil hyaloid material bands (H\&E staining; magnification, x20). H\&E, haematoxylin and eosin.

A

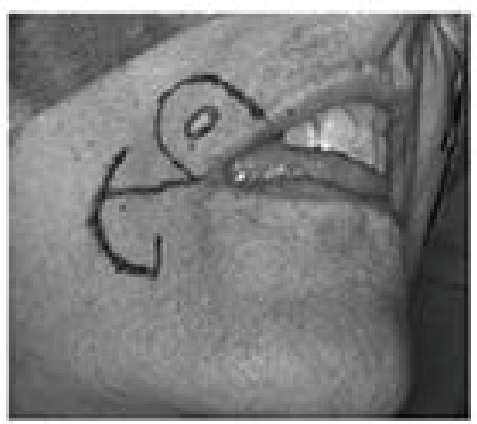

D

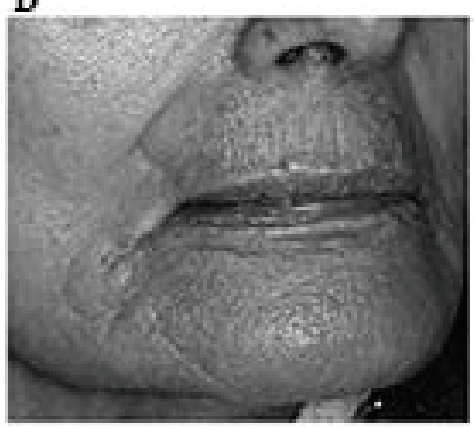

B

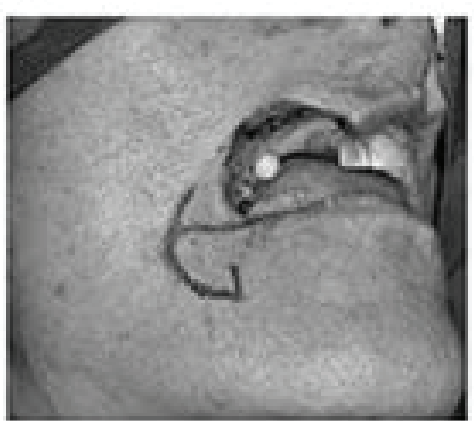

E

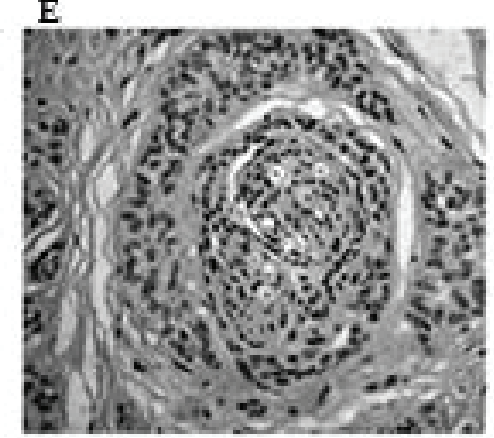

C

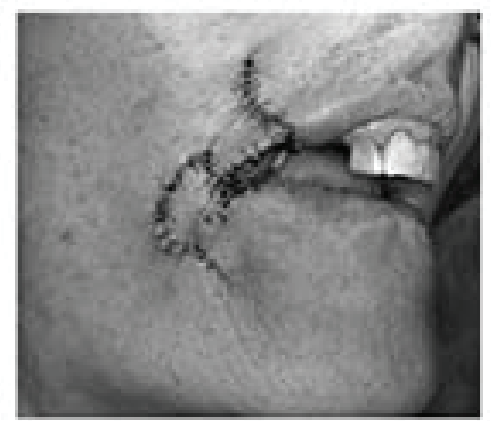

F

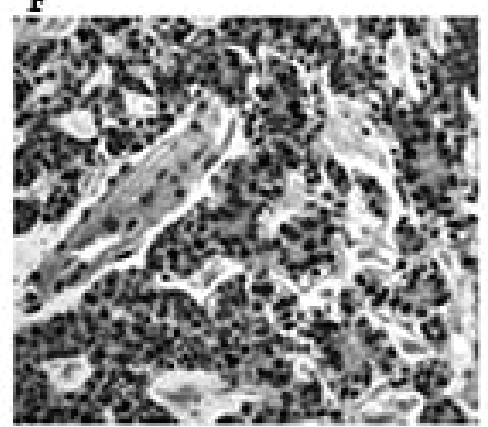

Figure 2. Case 2. (A) Preoperative view. (B) Intraoperative view following excision. (C) Immediate postoperative appearance, and (D) appearance 18 months postoperatively. (E) Focus of perineural invasion in adenoid cystic carcinoma (H\&E staining; magnification, x100). (F) Positive immunohistochemical results for p53 (magnification, x400). H\&E, haematoxylin and eosin.

who underlined its rarity; it is also worth mentioning the study by Gorlin et al (25), who pointed out that the incidence of ACC in the upper lip was $\sim 3 \%$. Subsequently, several studies have referred to ACC at this location, although very few of them have focused on its clinical behaviour and management. Waldron et al (4) reported 426 cases of intraoral minor salivary 
A

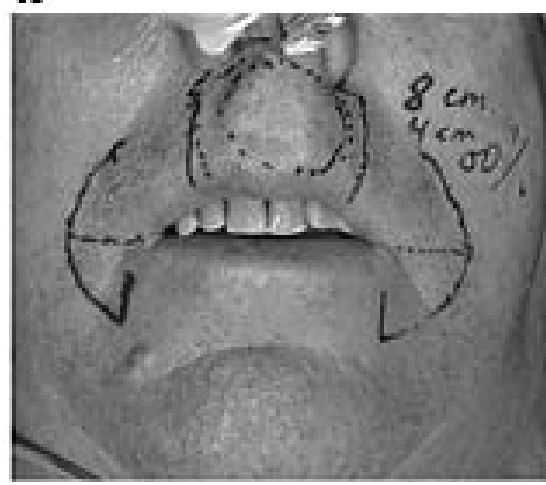

D

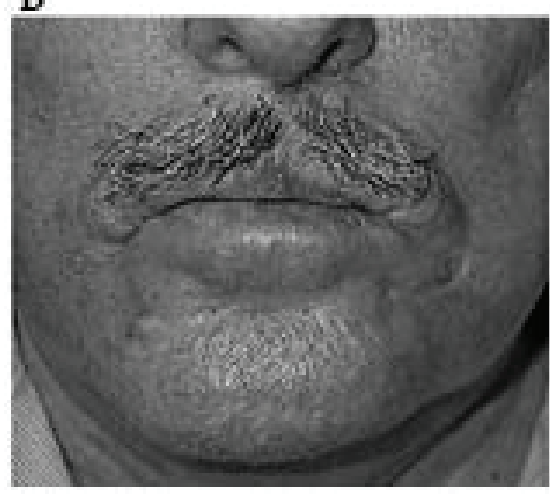

B

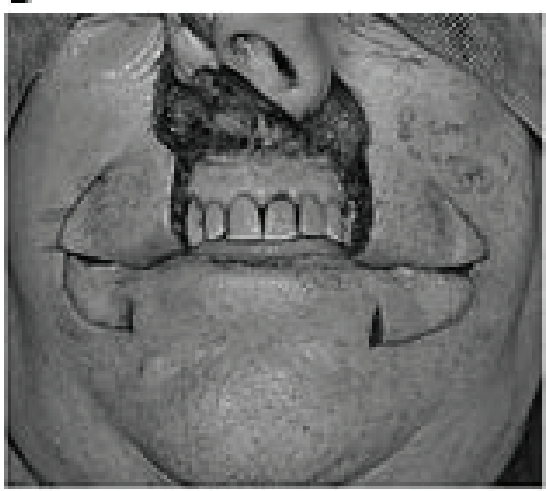

E

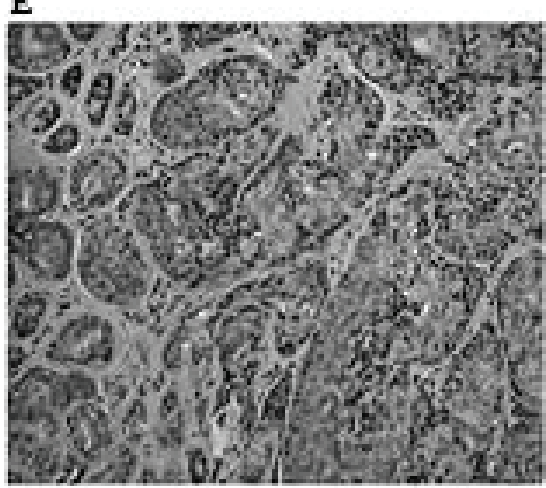

C

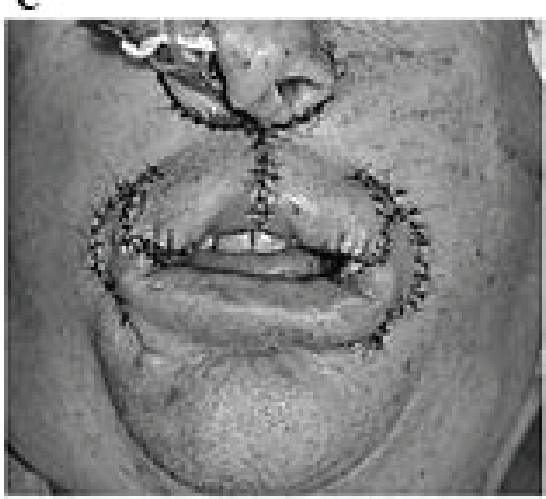

F

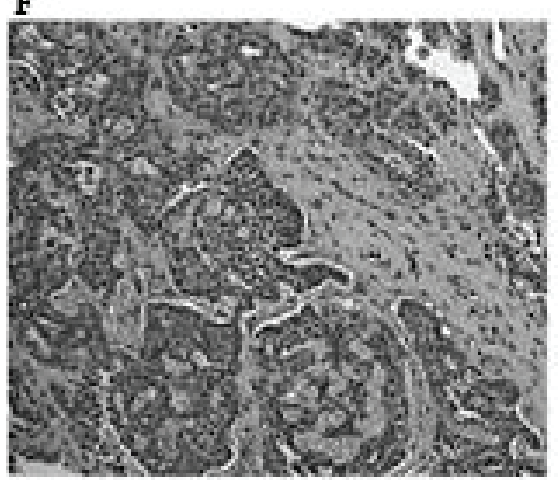

Figure 3. Case 3. (A) Preoperative view: Projected excision and bilateral Yu flap design for reconstruction. (B) Intraoperative view, revealing the defect following wide excision of the tumour. (C) Immediate postoperative appearance, and (D) one year after the procedure. (E) Details of the high-grade ACC of the upper lip, showing perineural invasion (right lower corner; H\&E staining; magnification, x10). (F) Lung metastasis from ACC, with prominent solid and microcystic patterns of growth. The histopathological features were similar to those of the solid subtype of salivary gland ACC (H\&E staining; magnification, x10). ACC, adenoid cystic carcinoma; H\&E, haematoxylin and eosin.

gland neoplasms, and identified two cases of ACC on the upper lip; Yih et al (26) identified one case out of 213; Pires et al (27) identified two cases out of 546; and Wang et al (28) identified six cases out of 397. Luna-Ortiz et al (29) presented a series of 59 cases of upper lip malignant neoplasms, and only one of these was ACC. Alfaro-Rubio et al (30) reported a case of ACC on the upper lip with a cervical lymph node metastasis 10 years after treatment of the primary tumour.

Upper lip ACC presents as a slow-growing nodule that commonly does not exhibit early significant symptoms, so it may pass unnoticed. The most frequent symptom in the series in the present study was the finding of a painless submucosal nodule on the upper lip. Due to its apparently benign slow evolution, patient diagnosis is often delayed (12). In patient 3, the period of time that elapsed from the first symptom to treatment was over 2 years following the initial removal of the primary lesion.

The biological behaviour of ACC has yet to be fully elucidated (31). Several aspects have been associated with a poor prognosis, including the clinical stage, tumour location, presence of metastatic nodules, symptoms-to-diagnosis interval, recurrence following treatment, histological subtype, nerve invasion, and positive surgical margins $(32,33)$. Histological features have also been correlated with the prognosis with inconsistent results. Several authors have suggested that the solid pattern appears to be more aggressive, and that it may be associated with an adverse clinical course and poor prog- nosis (32). From a histological point of view, the predominant patterns in the present case series were cribriform and solid. In case 1, a predominant cribriform pattern was reported without neural invasion. However, in patients 2 and 3, the subtype was less favourable, as a solid-predominant pattern was identified with evidence of neural invasion. On the other hand, other studies have not identified any correlation between histological subtype and clinical behaviour (34), or been able to link survival rates with the location or the clinical stage.

The infiltrative growth pattern and perineural invasion are other characteristics associated with the prognosis (19). This would explain the high risk of recurrence of this neoplasm, which could be interpreted as an incomplete surgical removal. Nevertheless, other authors have not identified any correlation between perineural invasion and prognosis (32). Similarly, a positive microscopic surgical margin is associated with a worse prognosis $(8,35)$. In these cases, postoperative radiotherapy is recommended. In the present case series, surgical resection was complete, and clear margins were achieved in all patients. Considering that lip tumours have a relatively easier surgical management compared with cancer in other oral cavity locations, the findings of the present study suggest that the prognosis of upper-lip ACC may be improved compared with other salivary glands.

The preferred treatment for upper-lip ACC is radical excision with immediate reconstruction (36). Resection must be complete, with a clear margin of at least $1 \mathrm{~cm}$ including the 
nearby nerves, to avoid recurrence, due to its propensity for perineural invasion (37). Although these tumours are highly radiosensitive and are thus responsive to radiotherapy, they are not radiocurable. For this reason, radiation therapy may be indicated in unresectable tumours (38). For tumours confined to the lip, excision with clear surgical margins and no evidence of nerve invasion can achieve good results. In cases 1 and 2 in the present study, the tumour was located in an accessible lip area, and surgical resection was complete with clear margins. Patient 3 revealed a more aggressive behaviour, with lung metastasis and local recurrence observed following a previous non-curative surgical resection. Despite wide excision, a very close follow-up of patients is required for at least 10 years in order to detect local recurrences and distant metastases (5). Postoperative radiotherapy may be indicated with positive surgical margins, or when perineural invasion or bone infiltration occur $(3,10,37,39-41)$.

Following a radical resection of a lip tumour, immediate reconstruction is essential to restore functional competence and to achieve optimal aesthetic results. In the literature, several methods have been described for reconstructing upper lip defects, indicating that there is no procedure that may be applied unilaterally. Reverse Yu flap is a rotation-advancement flap described in 2010 by Belmonte-Caro et al (23) as a modification of the original Yu flap designed in 1989 for repair of full-thickness defects of the lower lip (42). It may be either unilateral or bilateral, and represents a highly reliable technique that combines the advantages of both rotation and advancement flaps with good functional and aesthetic results in the upper lip reconstruction. This procedure was first described for the reconstruction of a defect that involved nearly half of the upper lip $(35 \times 35 \mathrm{~mm})$ in a 66 -year-old man following resection of a squamous cell carcinoma. There were no postoperative complications, and the results were very satisfactory in terms of function and aesthetics (23). In all three cases of the present study, the result was a functional lip, able to control saliva, mastication and speech. Furthermore, the stoma size was maintained, and labial sphincter function was preserved. Good aesthetic results were obtained, since scars were placed in the nasolabial fold and the grooves of the commissure following the direction of the wrinkles of the face, and color and thickness of the reconstructed skin, were similar of those of the original lip skin. A symmetrical upper lip was achieved with minimal donor site deformity, and produced less microstomia than other flaps. The main disadvantages of the method are that it is a relatively more complicated procedure to perform, and it may be more time-consuming compared with other techniques.

To date, there have been only 12 well-documented cases of reverse Yu flap reported in the English literature. Lee et al (43) in 2012 reported two cases of reconstruction of upper-lip defects, following a case of squamous cell carcinoma and a dog bite, respectively. These cases demonstrated that this technique may also be used in young patients with little or no skin redundancy, and not only for an oncological purpose. Li et al (44) reported the largest case series to date, using a reverse Yu flap in eight patients with various types of tumour (squamous cell carcinoma, basal cell carcinoma and malignant melanoma). These authors recommended this procedure to close lateral or central defects up to two-thirds the length of 
the upper lip. García de Marcos et al (45) in 2014 described the first case of a bilateral reverse Yu flap to repair almost two-thirds of the upper paramedian lip following excision of a Merkel cell carcinoma, obtaining very good results. The present study adds three more cases, as well as lending support to the reliability of this single-stage procedure for reconstructing full-thickness lateral defects from one-third to two-thirds of the total upper lip length in patients with ACC.

In conclusion, reverse Yu flap has been predominantly used for the reconstruction of full-thickness defects involving up to two-thirds of the upper lip. The findings of the present study indicate that it may be a particularly valuable method for the simultaneous reconstruction of medium-sized defects following radical excision of ACC. It is easy to raise and has a high success rate, with good aesthetic and functional results and minimal donor site morbidity. When the indications and contraindications are respected and used with knowledge of its clinical utility and limitations, a well-planned reverse Yu flap constitutes an elegant surgical option that should be taken into consideration when reconstructing the upper lip.

\section{References}

1. El-Naggar AK and Huvos AG: Adenoid cystic carcinoma. In: Barnes L, Eveson JW, Reichart P, Sidransky D (Eds), Pathology and Genetics of Head and Neck Tumours. IARC Press: Lyon. World Health Organization (WHO): pp 221-222, 2005.

2. Perzin KH, Gullane P and Clairmont AC: Adenoid cystic carcinoma arising in salivary glands: A correlation of histologic features and clinical course. Cancer 42: 265-282, 1978.

3. Darling MR, Schneider JW and Phillips VM: Polymorphous low-grade adenocarcinoma and adenoid cystic carcinoma: A review and comparison of immunohistochemical markers. Oral Oncol 38: 641-645, 2002.

4. Waldron CA, el-Mofty SK and Gnepp DR: Tumors of the intraoral minor salivary glands: A demographic and histologic study of 426 cases. Oral Surg Oral Med Oral Pathol 66: 323-333, 1988.

5. Triantafillidou K, Dimitrakopoulos J, Iordanidis F and Koufogiannis D: Management of adenoid cystic carcinoma of minor salivary glands. J Oral Maxillofac Surg 64: 1114-1120, 2006.

6. Bjørndal K, Krogdahl A, Therkildsen MH, Overgaard J, Johansen J, Kristensen CA, Homøe P, Sørensen CH, Andersen E, Bundgaard T, et al: Salivary gland carcinoma in Denmark 1990-2005: A national study of incidence, site and histology. Results of the Danish Head and Neck Cancer Group (DAHANCA). Oral Oncol 47: 677-682, 2011.

7. Bradley PJ: Adenoid cystic carcinoma of the head and neck: A review. Curr Opin Otolaryngol Head Neck Surg 12: 127-132, 2004.

8. Tomich CE: Adenoid cystic carcinoma. In: Surgical Pathology of the Salivary Glands. Ellis GL, Auclair PL, Gnepp DR (eds) Saunders, Philadelphia, pp333-349, 1991.

9. Avery CM, Moody AB, McKinna FE, Taylor J, Henk JM and Langdon JD: Combined treatment of adenoid cystic carcinoma of the salivary glands. Int J Oral Maxillofac Surg 29: 277-279, 2000.

10. Fordice J, Kershaw C, El-Naggar A and Goepfert H: Adenoid cystic carcinoma of the head and neck: Predictors of morbidity and mortality. Arch Otolaryngol Head Neck Surg 125: 149-152, 1999.

11. Spiro RH and Huvos AG: Stage means more than grade in adenoid cystic carcinoma. Am J Surg 164: 623-628, 1992

12. Huang M, Ma D, Sun K, Yu G, Guo C and Gao F: Factors influencing survival rate in adenoid cystic carcinoma of the salivary glands. Int J Oral Maxillofac Surg 26: 435-439, 1997.

13. Norberg-Spaak L, Dardick I and Ledin T: Adenoid cystic carcinoma: Use of cell proliferation, BCL-2 expression, histologic grade, and clinical stage as predictors of clinical outcome. Head Neck 22: 489-497, 2000.
14. Bianchi B, Copelli C, Cocchi R, Ferrari S, Pederneschi N and Sesenna E: Adenoid cystic carcinoma of intraoral minor salivary glands. Oral Oncol 44: 1026-1031, 2008.

15. Weber RS, Palmer JM, el-Naggar A, McNeese MD, Guillamondegui OM and Byers RM: Minor salivary gland tumours of the lip and buccal mucosa. Laryngoscope 99: 6-9, 1989.

16. Seaver PR Jr and Kuehn PG: Adenoid cystic carcinoma of the salivary glands: A study of ninety-three cases. Am J Surg 137: 449-455, 1979

17. Giannini PJ, Shetty KV, Horan SL, Reid WD and Litchmore LL: Adenoid cystic carcinoma of the buccal vestibule: A case report and review of the literature. Oral Oncol 42: 1029-1032, 2006.

18. Garcia de Marcos JA, Calderón-Polanco J, Poblet E, del Castillo-Pardo de Vera JL, Arroyo-Rodríguez S, Galdeano-Arenas M and Dean-Ferrer A: Primary adenoid cystic carcinoma of the mandible: Case report and review of the literature. J Oral Maxillofac Surg 66: 2609-2615, 2008.

19. Hemprich A and Schmidseder R: The adenoid cystic carcinoma. Special aspects of its growth and therapy. J Craniomaxillofac Surg 16: 136-139, 1988.

20. Abbe R: A new plastic operation for the relief of deformity due to double harelip. Plast Reconstr Surg 42: 481-483, 1968.

21. Karapandzic M: Reconstruction of lip defects by local arterial flaps. Br J Plast Surg 27: 93-97, 1974.

22. Gillies HD and Millard DR: The principles and art of plastic surgery. Butterworth, London, 1957.

23. Belmonte-Caro R, Infante-Cossio P, Garcia-Perla-Garcia A and Torres-Carranza E: Reverse Yús flap for upper lip reconstruction. J Plast Reconstr Aesthet Surg 63: 148-150, 2010.

24. Pizer ME and Dubois DD: Adenoid cystic carcinoma of the upper lip. Oral Surg Oral Med Oral Pathol 59: 70-73, 1985.

25. Gorlin RJ, Goldman HM and Hurt W: Thoma's oral pathology. J Periodontol 43: 575-577, 1972.

26. Yih WY, Kratochvil FJ and Stewart JC: Intraoral minor salivary gland neoplasms: Review of 213 cases. J Oral Maxillofac Surg 63: 805-810, 2005

27. Pires FR, Pringle GA, de Almeida OP and Chen SY: Intra-oral minor salivary gland tumors: A clinicopathological study of 546 cases. Oral Oncol 43: 463-470, 2007.

28. Wang D, Li Y, He H, Liu L, Wu L and He Z: Intraoral minor salivary gland tumors in a chinese population: A retrospective study on 737 cases. Oral Surg Oral Med Oral Pathol Oral Radiol Endod 104: 94-100, 2007.

29. Luna-Ortiz K, Güemes-Meza A, Villavicencio-Valencia V and Mosqueda-Taylor A: Upper lip malignant neoplasms. A study of 59 cases. Med Oral Patol Oral Cir Bucal 17: e371-e376, 2012.

30. Alfaro-Rubio A, Sanmartin Jiménez O, Serra-Guillén C, Requena Caballero C, Hueso Gabriel L, Botella-Estrada R, Nagore Enguídanos E, Llombart Cussac B and Guillén Barona C: Adenoid cystic carcinoma. Actas Dermosifiliogr 97: 578-580, 2006 (In Spanish).

31. Kuhel W, Goepfert H, Luna M, Wendt C and Wolf P: Adenoid cystic carcinoma of the palate. Arch Otolaryngol Head Neck Surg 118: 243-247, 1992.

32. Nascimento AG, Amaral AL, Prado LA, Kligerman J and Silveira TR: Adenoid cystic carcinoma of salivary glands. A study of 61 cases with clinicopathologic correlation. Cancer 57: 312-319, 1986.

33. Shingaki S, Saito R, Kawasaki T and Nakajima T: Adenoid cystic carcinoma of the major and minor salivary glands. A clinicopathological study of 17 cases. J Maxillofac Surg 14: 53-56, 1986.

34. Spiro RH, Huvos AG and Strong EW: Adenoid cystic carcinoma: Factors influencing survival. Am J Surg 138: 579-583, 1979.

35. Brown JS: Prognostic factors in oral, oropharyngeal and salivary gland cancer. In: Maxillofacial Surgery. Booth PW, Schendel SA Hausamen J-E (eds). Vol 1. Churchill Livingstone, Edinburgh London, New York, pp291-308, 1999.

36. Kokemueller H, Eckardt A, Brachvogel P and Hausamen JE: Adenoid cystic carcinoma of the head and neck-a 20 years experience. Int J Oral Maxillofac Surg 33: 25-31, 2004.

37. Garden AS, Weber RS, Morrison WH, Ang KK and Peters LJ: The influence of positive margins and nerve invasion in adenoid cystic carcinoma of the head and neck treated with surgery and radiation. Int J Radiat Oncol Biol Phys 32: 619-26, 1995.

38. Hirota $\mathrm{J}$ and Osaki T: Primary central adenoid cystic carcinoma of the mandible. J Oral Maxillofac Surg 47: 176-179, 1989.

39. Cohen AN, Damrose EJ, Huang RY, Nelson SD, Blackwell KE and Calcaterra TC: Adenoid cystic carcinoma of the sub-mandibular gland: A 35-year review. J Otolaryngol Head Neck Surg 131: 994-1000, 2004. 
40. Huber PE, Debus J, Latz D, Zierhut D, Bischof M, Wannenmacher M and Engenhart-Cabillic R: Radiotherapy for advanced adenoid cystic carcinoma: Neutrons, photons or mixed beam? Radiother Oncol 59: 161-167, 2001.

41. Maciejewski A, Szymczyk C and Wierzgoń J: Outcome of surgery for adenoid cystic carcinoma of head and neck region. J Craniomaxillofac Surg 30: 59-61, 2002.

42. Yu JM: A new method for reconstruction of the lower lip after tumor resection. Eur J Plast Surg 12: 155-159, 1989.

43. Lee J, Oh SJ, Jung SW and Koh SH: Combined rotation and advancement flap reconstruction for a defect of the upper lip: 2 cases. Arch Plast Surg 39: 244-248, 2012.
44. Li ZN, Li RW, Tan XX, Xu ZF, Liu FY, Duan WY, Fang QG, Zhang $X$ and Sun C: Yu's flap for lower lip and reverse Yu's flap for upper lip reconstruction: 20 years experience. Br J Oral Maxillofac Surg 51: 767-772, 2013.

45. García de Marcos JA, Heras Rincón I, González Córcoles C, Sebastián Alfaro M, Poblet Martínez E and Arroyo Rodríguez S: Bilateral reverse Yu flap for upper lip reconstruction after oncologic resection. Dermatol Surg 40: 193-196, 2014. 